Case Report

\title{
A Shot That Hits the Tumor: Incidental Finding of Early Colon Cancer in a Gunshot Wound Specimen-The Role of Pathologic Examination
}

\author{
Neda Soleimani ${ }^{1}{ }^{1}$ and Sara Pakbaz ${ }^{2}$ \\ ${ }^{1}$ Department of Pathology, Shiraz University of Medical Sciences, Shiraz, Iran \\ ${ }^{2}$ Department of Pathology, Toronto General Hospital, University of Toronto, Canada \\ Correspondence should be addressed to Neda Soleimani; soleimani_n@sums.ac.ir
}

Received 9 December 2018; Revised 10 March 2019; Accepted 31 March 2019; Published 15 April 2019

Academic Editor: Mark Li-cheng Wu

Copyright ( 2019 Neda Soleimani and Sara Pakbaz. This is an open access article distributed under the Creative Commons Attribution License, which permits unrestricted use, distribution, and reproduction in any medium, provided the original work is properly cited.

\begin{abstract}
This report presents incidental finding of early colorectal cancer in an adult patient with gunshot injury. The patient was a $41 \mathrm{y} / \mathrm{o}$ man, transferred to our center due to gunshot wound to his abdomen and back. A well differentiated adenocarcinoma, stage I, was incidentally identified during pathologic examination on his segmental proctectomy specimen. This singular case highlights the necessity of caring for all removed tissues, indicating how important they are for both clinicians and pathologists.
\end{abstract}

\section{Introduction}

Colorectal cancer is a main cause of morbidity and mortality throughout the world [1]. It is the third most common cancer worldwide and the fourth most common cause of death [2]. Patient survival is highly dependent upon stage of disease at diagnosis. We would like to present incidental finding of early rectal cancer (stage I) in a $41 \mathrm{y} / \mathrm{o}$ man with gunshot wound to his abdomen.

\section{Case Report}

A man aged 41 years was transferred to our center at Shiraz University of Medical Sciences, Iran, sustaining gunshot wound to his back and abdomen. In terms of past medical history, he was a rural man with poor healthcare and traditional drug addict (flexible dosing) with no family history of cancer. There was not any history of weight loss, anorexia, and change in bowel habit. Although he was hemodynamically stable, initial evaluation showed retroperitoneal hematoma (about $500 \mathrm{cc}$ blood) with expansion from zone III to zone I and also S2 vertebral fracture.

At the laparotomy, patchy necrosis of rectum was detected and short segmental resection $(5.5 \mathrm{~cm}$ in length) was performed. Although, there was not any gross evidence of abnormal finding during operation, as a rule in our department any specimen removed from human body should be sent to pathology examination and the specimen underwent pathologic assessment.

Grossly there was edema, multifocal necrosis, and a small polypoid firm lesion measuring $1 \times 1 \times 0.5 \mathrm{~cm}$ near one margin, histologically showing well differentiated adenocarcinoma, hard to believe (Figure 1). Microscopic tumor extension was limited to submucosa (T1), signed out as stage I (Figure 2).

\section{Discussion}

Surgical pathology is the study of tissues removed from patients, covering physical examination of tissue with naked eye as well as microscopic examination. Any specimen would be potentially considered as malignant, and even very experienced pathologists are often surprised when comparing the macroscopic diagnosis with the histopathologic slides. Therefore careful orientation, gross examination, and proper sectioning of surgical specimens are mandatory. It is not hard to diagnose malignancy through microscopic examination if the sections are taken from proper sites. Although histologic examination of the vast majority of trauma specimens shows 


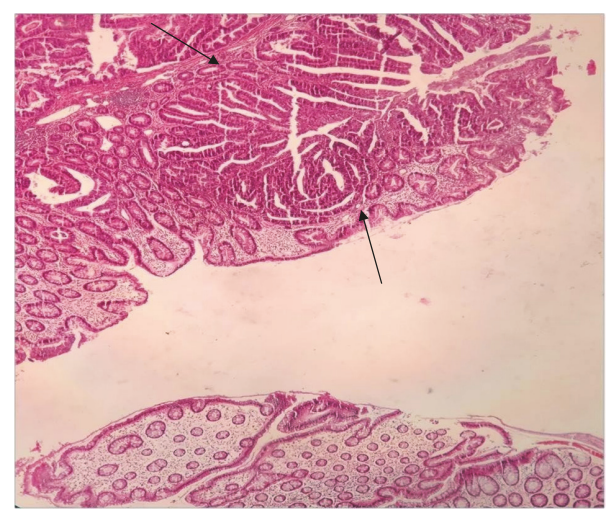

FIGURE 1: Well differentiated adenocarcinoma at one margin of colon specimen (arrow) (H\&E x 10).

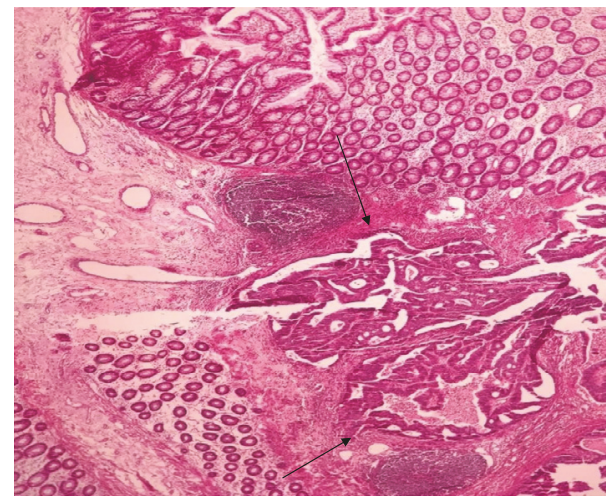

Figure 2: Tumor invades to submucosa (arrow) (H\&E x 20).

signs of acute inflammation, sometimes it is done to check the viability of resected margins as done in our case [3]. The surgeons should always keep in mind that it is important to follow the pathologic reports in all cases, not just because there might be malignancy (like ours), but sometimes other pathologies that may require further postoperative managements are found. Examples include incidental finding of Rosai-Dorfman disease in tonsillectomy specimen of a 4-year-old girl, primary fallopian tube carcinoma during bilateral salpingooophorectomy for removal of ovarian cyst, and gall bladder adenocarcinoma during pathological evaluation of cholecystectomy specimens [4-6]. Once we found unexpected malignancy-in fact any unexpected pathology is a critical value-we called a surgeon at the same time to do better evaluation [7]. Fortunately, in the lesion that we found, microscopic tumor extension was just limited to submucosa, without any lymph node involvement or metastasis, so it was signed out as stage I.

\section{Conflicts of Interest}

The authors declare that they have no conflicts of interest.

\section{References}

[1] World Health Organization Cancer Incidence in Five Continents, The World Health Organization And The International Agency for Research on Cancer, Lyon, 2002.

[2] World Cancer Research Fund and American Institute for Cancer Research Food, Nutrition, physical activity, and the prevention of cancer: a global perspective, vol. 67, American Institute for Cancer Research, Wash, D.C., USA, 2007.

[3] J. L. Connolly, S. J. Schnitt, H. H. Wang, J. A. Longtine, A. Dvorak, and H. F. Dorak, International Journal of Gynecology \& Obstetrics, vol. 39, BC Decker, Hamilton, 6th edition, 2003.

[4] J. Qualtieri and S. B. Kahwash, "Incidental finding of isolated Rosai- Dorfman disease in the tonsils of a 4 - year- old girl: a case report and a brief review of current practice in tonsillectomy specimen handling," Open Journal of Pathology, vol. 3, pp. 7-9, 2013.

[5] F. Basak, M. Hasbahceci, T. Canbak et al., "Incidental findings during routine pathological evaluation of gall bladder specimens: review of 1,747 elective laparascopic cholecystectomy cases," The Annals of The Royal College of Surgeons of England, vol. 98, no. 04, pp. 280-283, 2016.

[6] N. Lodha, K. Bharati, N. Saxena, and S. Hingway, "An incidental finding of primary carcinoma of the fallopian tube: a case report," International Journal of Research in Medical Sciences, vol. 4, no. 11, pp. 5077-5079, 2016.

[7] J. F. Silverman, V. LiVolsi, C. D. M. Fletcher et al., "Critical diagnoses (critical values) in anatomic pathology," American Journal of Clinical Pathology, vol. 125, no. 6, pp. 815-817, 2006. 


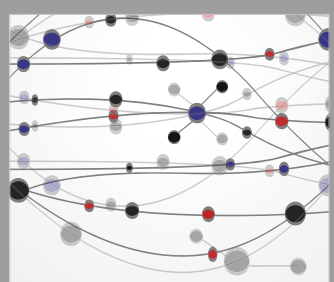

The Scientific World Journal
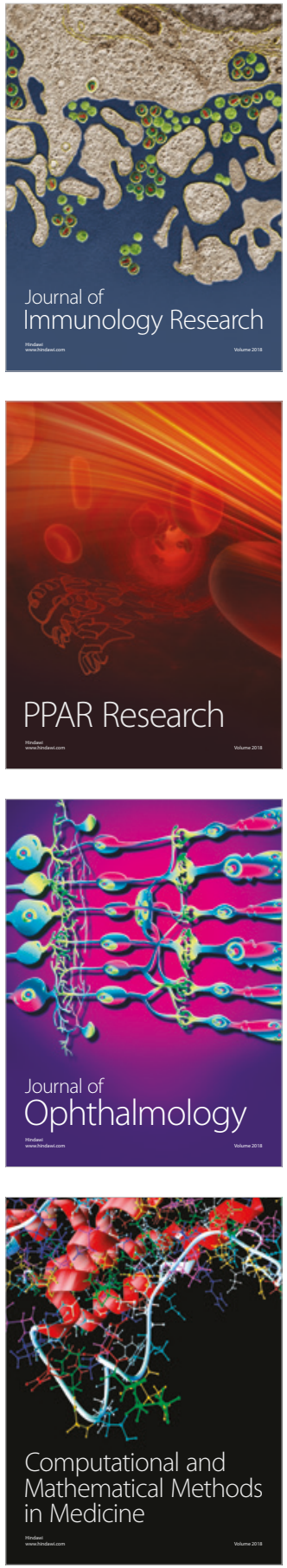

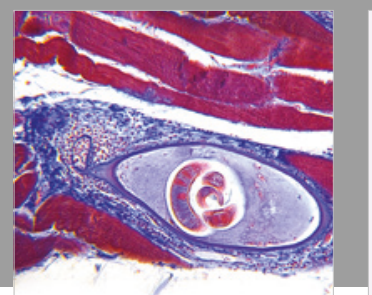

Gastroenterology Research and Practice

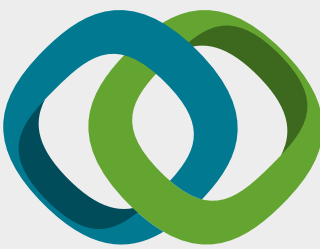

\section{Hindawi}

Submit your manuscripts at

www.hindawi.com
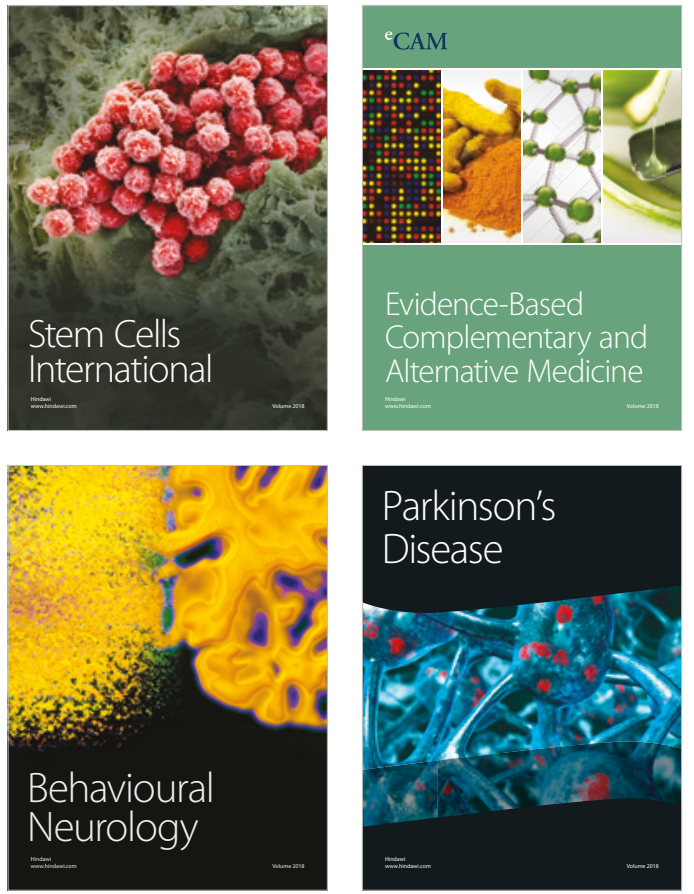

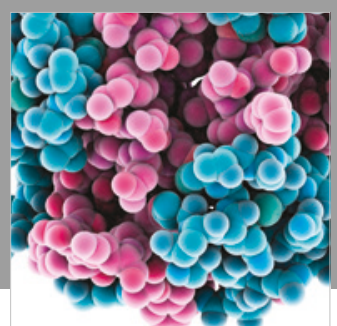

ournal of

Diabetes Research

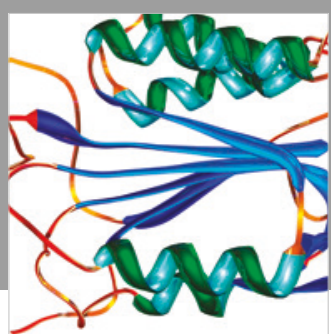

Disease Markers
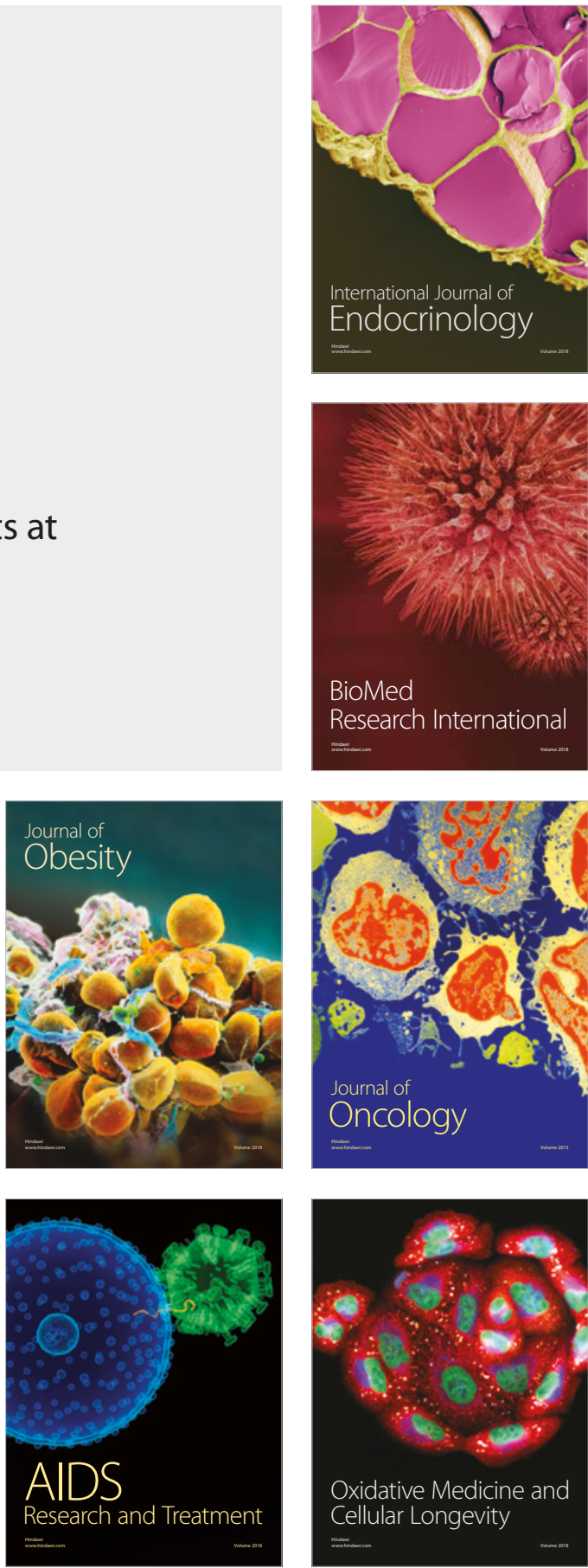